\title{
Informação, trabalho e tempo livre: políticas de informação para o século XXI
}

\section{Icléia Thiesen Magalhães Costa}

\section{Resumo}

Discussão e problematização das ações de informação no contexto da chamada sociedade global, que põe em cena dilemas, conflitos e paradoxos, sacudindo as cidades, redesenhando a geografia do mundo e desvelando aos nossos olhos a exacerbação da intolerância materializada em guerras civis e étnicas. Diante do processo mais amplo de desindustrialização, das novas modalidades de trabalho, precário e irregular, alguns desafios se impõem: como desenhar e direcionar políticas de informação que venham a dar conta de uma imensa massa de excluídos,

desempregados, exilados, marginalizados? No plano coletivo, existiriam agenciamentos que viessem a dar conta das novas subjetividades coletivas e das múltiplas identidades em jogo? Diante desse globalismo, é preciso problematizar outros valores e colocar em pauta novas formas de cidadania. A nova revolução deverá ser ética e estética.

\section{Palavras-chave}

Políticas de informação; Trabalho; Tempo livre.

\section{INTRODUÇÃO}

Há muitas décadas circulam em nosso imaginário afirmativas legitimadas pela ciência e pela técnica dando conta de que estamos na era da informação e, mais do que isso, que informação é poder. Nesse contexto, com o auxílio da informática a informação toma lugar de destaque no cenário mundial. $O$ desafio que se impõe à ciência, nos últimos tempos, prendese à recuperação de um volume quase planetário de informações, no menor tempo possível.

Enquanto saber voltado para os fenômenos de informação, a ciência da informação surge no período pós-guerras por razões institucionais e estratégicas. Sua marca de batismo coincide com a própria institucionalização da ciência que, segundo $\mathrm{Morel}^{2}$, tem como marco teórico o Projeto Manhatan, "que reuniu nos Estados Unidos as pesquisas sobre a bomba atômica durante a Segunda Guerra", fato que estabelece a supremacia da ciência norte-americana e a decadência da ciência européia.

A partir de então os governos passam a definir suas políticas de ciência e tecnologia, assim como suas políticas de informação. É bom lembrar que estávamos em plena Guerra Fria, período em que se impunha a institucionalização de mecanismos de geração, processamento e controle de uma imensa massa de informações a serem recuperadas. Desde então, o Estado passa a gerenciar a informação científica e tecnológica por meio de ministérios e conselhos de pesquisa. Tais políticas de pesquisa voltavam-se fortemente para os interesses industriais.
Após mais de 40 anos, um processo de desindustrialização, em curso nas sociedades ocidentais, vem provocando inúmeras transformações no campo social. Fala-se indiscriminadamente em globalização, parcerias, economias abertas, mercados consumidores mundializados, sem fronteiras para além dos atlas escolares, e novas relações de trabalho. A mídia nos faz ver tais tendências como fenômeno irreversível, pois é suposto ser obra de forças deterministas que não nos permitem alternativas. A palavra de ordem é aderir ou sucumbir. Tal adesão significa abraçar novas e cada vez mais novas tecnologias de informação e de comunicação, constantemente transformadas e anunciadas como panacéias.

Nesse caso, não se trata mais de promover ações, produzir informações e articular políticas de informação com vistas ao trabalho, mas ao não-trabaIho, ao tempo livre que vai guiar a nova humanidade do século XXI. Este artigo tem por objetivo refletir sobre as perspectivas das ações de informação no contexto da chamada sociedade global, que põe em cena dilemas, conflitos e paradoxos, sacudindo as cidades, redesenhando a geografia do mundo e desvelando aos nossos olhos a exacerbação da intolerância materializada em guerras civis e étnicas.

Estaremos preparados para abandonar as determinações que há mais de 50 anos nos formam e informam? Como direcionar essas políticas para as novas formações sociais e institucionais em curso? Quais as novas palavras de ordem dos discursos em vias de formação? Como entender fenômenos dessa natureza e traduzi-los em práticas de vida, que levem em conta as 
novas subjetividades coletivas e as múltiplas alteridades em jogo? Em que medida as questões de identidade serão levadas em conta? Que valores serão cultivados numa sociedade que não mais privilegia o trabalho? De que tempo poderemos então falar nessa sociedade que certamente não mais será a da informação?

As respostas devem ser buscadas e construídas em planos locais e globais, desde que a chamada revolução das tecnologias de informação e de comunicação passe por um processo de inclusão de novos conteúdos educativos, culturais e políticos, em vez de limitarse a gerir a sociedade, promovendo a desigualdade social e a tirania de identidades culturais que promovem a guerra para garantir hegemonia. Diante desse globalismo ${ }^{3}$ é preciso problematizar outros valores e colocar em pauta novas formas de cidadania. A nosso ver, a nova revolução deverá ser ética e estética. Senão vejamos.

\section{A PRECARIZAÇÃO DO TRABALHO}

No quadro mais amplo do processo de globalização das sociedades, fica evidente a incidência de fenômenos como o desemprego, a precarização do trabalho, a desregulamentação, a flexibilização das relações capital-trabalho. O que vem a ser tudo isso? Para além dos discursos presentes na mídia, trata-se na verdade de um conjunto de fenômenos que convivem nas cidades globais, subsumindo realidades ainda indiscerníveis. Os especialistas - economistas, sociólogos, geógrafos, historiadores, filósofos - nem de longe conseguem clarear esse quadro social que se desenha diante de nossos olhos, em uma babel de fim de século.

O fato é que se pode depreender desses acontecimentos globais processos de exclusão, que tornam visíveis não apenas os desempregados, homens e mulheres, mas os trabalhadores temporários, os destituídos de pátria, os exilados, os marginalizados, mas uma imensa massa de perdedores desesperançados. As cidades transformamse, diante de nossos olhos, em um grande paiol, em uma escalada de violência sem precedentes, especialmente se pensarmos no avanço técnico conquistado em tão pouco tempo nas últimas décadas.

Para Bourdieu 4 , a precariedade está em toda parte, entendendo-se por esse termo as posições temporárias e interinas, cujos efeitos são visíveis de duas formas ou em duas direções: 1) para os desempregados significa a desestruturação de sua existência e a degradação de suas relações com o mundo, com o tempo e o espaço; 2) em relação aos que se encontram no mercado de trabalho, mesmo em condições de aparente estabilidade, tratase de um fantasma que atormenta, colocando em pauta a ameaça velada de tornarem-se futuros e eventuais desempregados.

O discurso que circula nos meios de comunicação e nas organizações deixa claro e estabelecido que o emprego é um privilégio e que pode ser perdido a qualquer tempo. Por ironia da razão, se é que se pode atribuir a ela as mazelas da economia globalizada - uma escolha política que privilegia a economia como a única maneira de conduzir a sociedade - após um longo processo histórico de fixação do trabalhador ao espaço da produção, à custa de tantas lutas para algumas conquistas, sendo a principal delas a liberdade, hoje o capitalismo, em sua fase mais cruel desemprega e prescinde do mesmo trabalhador, agora desmobilizado, desregulamentado, desvalorizado. Otrabalhador, o funcionário, o assalariado enfrentam agora os dissabores da incerteza, do desemprego, da precarização do trabalho, numa época em que a exclusão destrói os laços sociais e ameaça cada vez mais a vida das cidades.

A antiga sociedade disciplinar, característica do capitalismo de produção centrada na exploração do trabalho industrial, que estamos deixando para as instâncias do passado, está sendo substituída por uma sociedade de controle, que traz à tona um capitalismo de circulação e de comunicação originado na esteira das mutações tecnológicas da era da informatização planetária, legitimada pelo discurso neoliberal guiado pelo mercado. O controle social via confinamento dá lugar a um controle em rede, aberto, conectável e contínuo, móvel e fluido, que tem a seu favor um marketing universal e a
Internet.

No âmbito dessas transformações, as novas info-sociedades globais trazem consigo a mais sutil crise das instituições, analisadas por Foucault no conjunto de sua obra, mas especialmente em Vigiar e Punir. Não se trata mais do modelo panóptico, mas da extensão para todo o campo social das estratégias de controle. E não é por acaso que hoje se fala em fábrica global ${ }^{5}$, revolucionando as condições de vida e trabalho. Se a empresa substitui a fábrica, o processo que está em curso redefine as instituições em seus novos papéis: "os hospitais abertos, o atendimento em domicílio e outros serviços já surgiram há muito tempo," ${ }^{\circ}$ com suas máquinas cibernéticas, os computadores e as redes de informação.

\section{INFORMAÇÃO PARA O TEMPO LIVRE?}

Se todas as visões e previsões se materializarem no campo social, uma questão precisa ser respondida: se durante tanto tempo o trabalhador foi condicionado às instâncias da produção, filho que é do processo de industrialização de longa duração, que novos agenciamentos coletivos podem ser problematizados, com vistas à criação de novas formas de vida em sociedade, para além da perspectiva tempestuosa de que nos falam as mídias?

Em nosso entendimento, para que possamos pensar em políticas de informação para o próximo século - que também inaugurará um novo milênio - precisamos compreender para quem vamos defini-la. Importa saber também com qual intensidade, multiplicidade e pluralidade poderemos propor caminhos que venham a incluir, fortalecer e dar oportunidades aos que se encontram fora das cadeias de produção, mas que paradoxalmente nada sabem fazer com o tempo livre ${ }^{7}$, há tantos séculos simbolicamente condenado pelas instituições que regeram o trabalho nessa sociedade disciplinar, cujos últimos traços estão sendo apagados.

Por ironia da razão ou do destino coletivo, a nova humanidade que se avizinha terá que dar conta do estigma do 
não-trabalho, que tantas marcas negativas deixou nos povos ocidentais. Após ter sido docilizado nos processos de industrialização, o corpo social terá que inventar novos valores, com regras facultativas que nos permitam criar no heterogêneo sem a preocupação com identidades definidas de uma vez por todas, nas instâncias múltiplas da alteridade e da pura diferença.

Mas para isso será preciso, sem dúvida, uma nova imagem do pensamento. Uma estética da existência, com a criação de instâncias locais de subjetivação, em que acontecimentos singulares possam emergir como linha de fuga lúdica. Como proposto por Guattari $^{8}$, poderemos sair das categorias do tempo universal e unívoco e adentrar nos ritornelos, "que operam ao mesmo tempo em registros biológicos, socioculturais, maquínicos, cósmicos etc."

Para que seja possível inventar um novo social, conjurando os modelos da disciplina e do controle dos corpos e, para que um dia possamos falar da memória das instituições do terceiro milênio, hoje ainda deveremos problematizar novas paisagens em nossas cidades, pois

\section{Information, work and free time: information policies for the XXI century}

\begin{abstract}
Discussion and problematization of the information actions in the context of the so called global society, which brings up dilemmas, conflicts and paradoxes, shaking the cities, reshaping the world geography and display the exacerbation of materialized intolerance in civil and ethnical wars. In face of the widest process of disindustrialization, of new modalities of poor and irregular work, some challenges are overwhelming: how to draw and guide information policies which will be able to take care of the large mass of excluded, unemployed, exiled and marginalized people? In the overall plan, would there be agencies which could account for new collective subjectivities and multiple identities at stake? In face of this globalism, it is necessary problematize other values and include in the list of new forms of citizenship. The new revolution shall be ethical and aesthetical.
\end{abstract}

\section{Keywords}

Information policies; Work; Leasure. o pensamento terá inventado uma ética da solidariedade que, libertando o outro, libere-nos para o possível. Trata-se de produzir uma memória do futuro no jogo do acaso, como já havia sido indicado por Nietzsche. Ou, como sugerido por Guattari, restaurar uma "cidade subjetiva que engaja tanto os níveis mais singulares da pessoa quanto os níveis mais coletivos", reinventando o devir humano.

Quaisquer que sejam as soluções advindas dos planos e projetos oficiais, espera-se que passem por uma ampla conscientização de que é preciso questionar, duvidar e conjurar todos os fenômenos que atendam a determinados interesses, negligenciando as especificidades de cada região. A experiência histórica do século XX pode servir de farol a iluminar os caminhos a serem traçados em busca de uma sociedade inclusiva. Que a memória social possa tornar-se evidente a ponto de evitar que venhamos a repetir o passado, ao invés de inventar um futuro para além do sofrimento da humanidade.

\section{REFERÊNCIAS BIBLIOGRÁFICAS}

1. MOREL, R.L.de M. Ciência e estado: a política científica no Brasil. São Paulo: T. A Queiroz, 1979.

3. IANNI, O A era do globalismo. Rio de Janeiro: Civilização Brasileira, 1996. 342p. Segundo esse autor, trata-se de "uma configuração histórico-social abrangente, convivendo com as mais diversas formas sociais de vida e trabalho, mas também assinalando condições e possibilidades, impasses e perspectivas, dilemas e horizontes, (...) emergem ou ressurgem localismos, provincianismos, nacionalismos, regionalismos, colonialismos, imperialismos, etnicismos, racismos e fundamentalismos;" (p.235)

4. BOURDIEU, P. Contrafogos; táticas para enfrentar a invasão neoliberal. Rio de Janeiro: Jorge Zahar Editor, 1998.
5. DELEUZE, G. Conversações. Rio de Janeiro: Ed 34, 1992. "Foucault analisou muito bem o projeto ideal dos meios de confinamento, visível especialmente na fábrica: concentrar, distribuir no espaço; ordenar no tempo; compor no espaçotempo uma força produtiva cujo efeito deve ser superior à soma das forças elementares.(...) São as sociedades de controle que estão substituindo as sociedades disciplinares." (p.219, 220 e 221, respectivamente. Nas sociedades de controle, segundo esse autor, a empresa substituiu a fábrica.

6. Op. cit., p.216. O autor denuncia o que vem na retaguarda: "O que está sendo implantado, às cegas, são novos tipos de sanções, de educação, de tratamento. (...) Pode-se prever que a educação será cada vez menos um meio fechado, distinto do meio profissional - um outro meio fechado -, mas que os dois desaparecerão em favor de uma terrível formação permanente, de um controle contínuo se exercendo sobre o operário-aluno ou o executivouniversitário. Tentam nos fazer acreditar numa reforma da escola, quando se trata de uma liquidação." (p. 216) Mais adiante Deleuze denuncia: "a formação permanente tende a substituir a escola, e o controle contínuo substitui o exame. Este é o meio mais garantido de entregar a escola à empresa." (p.221)

7. MASI, Domenico de. A emoção e a regra; os grupos criativos na Europa de 1850 a 1950. Rio de Janeiro: José Olympio, 1999. O autor, professor de sociologia do trabalho, teórico da criatividade e do tempo livre, aponta para as características da era pós-industrial, que reserva ao homem o trabalho criativo, recuperando em sua obra as mais variadas experiências coletivas que se encontram registradas na história. Sua proposta é de organizar o tempo livre, a atividade artística e científica, e para isso fornece como patrimônio e inspiração vários exemplos advindos da velha Europa. A criatividade é entendida como filha dileta do equilíbrio entre razão e emoção, entre fantasia e senso prático. Sua manifestação mais forte se dá como fenômeno coletivo.

8. GUATTARI, F. Caosmose; um novo paradigma estético. Rio de Janeiro: Ed 34, 1991.

\section{Icléia Thiesen Magalhães Costa}

Museóloga (M.H.N. 1972) e bibliotecária (USU 1980), mestre e doutora em Ciência da Informação (IBICT/DEP, 1992 e 1997, respectivamente). Pesquisadora aposentada do IBGE (1997); professora adjunta da Unirio; Diretora da Escola de Biblioteconomia (Unirio).

E-mail: icleia@mail.sky.com.br 